\title{
Mowat-Wilson syndrome: neurological and molecular study in seven patients
}

\author{
Síndrome de Mowat-Wilson: estudo neurológico e molecular em sete pacientes \\ José Albino da Paz¹, Chong Ae Kim, Michael Goossens², Irina Giurgea², Maria Joaquina Marques-Dias ${ }^{3}$
}

\begin{abstract}
Objective: To present a seven-cases serie of Mowat-Wilson syndrome (MWS). Method: All patients with positive mutation for the ZEB2 were evaluated by a geneticist and a neurologist, with clinical and laboratorial characterization. Results: A peculiar facies and mental retardation were present in all patients. The Denver II scale showed intense delay in all aspects, especially fine motor and adaptive. Acquired microcephaly was observed in five patients. Only one patient did not present epilepsy. Epilepsy was focal and predominating in sleep, with status epilepticus in three patients. The initial seizure was associated with fever in most patients (4/6). The EEG showed epileptic focal activity (5/7). The imaging studies revealed total agenesis (4/7) and partial agenesis of the corpus callosum (1/7). Conclusion: Physicians who care for patients with mental retardation and epilepsy should be aware of SMW.
\end{abstract}

Keywords: Mowat-Wilson syndrome, epilepsy, corpus callosum agenesis, microcephaly, mental retardation.

RESUMO

Objetivo: Apresentar uma série de sete casos da síndrome de Mowat-Wilson (SMW). Método: Todos os pacientes com estudo positivo para a mutação ZEB2 foram avaliados por um geneticista e um neurologista, com a caracterização clínica e laboratorial. Resultados: Todos apresentavam fácies peculiar e retardo mental. A escala de Denver II evidenciou intenso atraso em todos os aspectos, sobretudo motor fino e adaptativo. Microcefalia adquirida foi observada em cinco pacientes. Apenas um paciente não apresentava epilepsia, sendo esta focal e predominando no sono, sendo relatado estado de mal em três pacientes. A crise inicial estava associada à febre na maioria dos pacientes (4/6). O EEG evidenciou atividade epiléptica focal na maioria (5/7). Ao estudo de imagem foi observada agenesia total (4/7) e parcial do corpo caloso (1/7). Conclusão: Médicos que lidam com pacientes com retardo mental e epilepsia devem saber distinguir as características peculiares da SMW.

Palavras-chave: síndrome de Mowat-Wilson, epilepsia, agenesia do corpo caloso, microcefalia, retardo mental.

Mowat-Wilson syndrome (MWS) is an autosomal dominant disorder that has been recently delineated ${ }^{1}$. The exact incidence rate is currently unknown because MWS is still an underdiagnosed condition, but it is believed to be at least 1 in 70,000 live births ${ }^{2}$. It is characterized by a distinctive facial appearance, including hypertelorism, sunken eyes, broad nasal bridge, broad and medial flared eyebrows, prominent columella, pointed chin and uplifted earlobes. Patients present with mental retardation and multiple congenital anomalies, including agenesis of the corpus callosum (ACC), Hirschsprung disease (HD), congenital heart defects, and urogenital anomalies.

There is no consensus on clinical diagnostic criteria, but all MWS patients have mental retardation - usually severe - and a characteristic facial gestalt. Most individuals present with microcephaly and epilepsy and have one or more congenital anomalies (HD, ACC, cardiac defects, urogenital anomalies, and hypospadias), but none of these traits are obligatory. Other commonly associated features include impaired or absent speech with relatively spared receptive language and distinct behavior patterns, generally with a happy personality ${ }^{2}$.

MWS is caused by heterozygous deletions or point mutations in the Zinc finger E-box-binding homeobox 2 gene (ZEB2), at locus 2q22-23,4. The ZEB2 gene consists of 10 exons spanning approximately $70 \mathrm{~kb}$. It codes for SIP 1 (Smad interacting protein 1), a multidomain protein first identified as a transcriptional co-repressor in the transforming growth

\footnotetext{
${ }^{1}$ Unidade de Neurologia e Genética, Instituto da Criança, Hospital das Clínicas, Universidade de São Paulo, Sao Paulo SP, Brazil;

${ }^{2}$ Service de Biochimie Génétique, Hôpital Henri Mondor, Créteil, France;

${ }^{3}$ Departamento de Neurologia, Faculdade de Medicina, Universidade de São Paulo, Sao Paulo SP, Brazil.

Correspondence: José Albino da Paz; Unidade de Neurologia, Instituto da Criança, Hospital das Clínicas, Universidade de São Paulo; Av. Dr. Enéas de Carvalho Aguiar, 647; 05403-000 São Paulo SP, Brasil; E-mail: jose.paz@hc.fm.usp.br

Conflict of interest: There is no conflict of interest to declare.

Received 13 June 2014; Received in final form 10 September 2014; Accepted 30 September 2014.
} 
factor- $\beta$ (TGF- $\beta$ ) signaling pathway, by directly binding to promoters and interacting with Smad proteins 1, 2, 3, and $5^{5}$. ZEB2 is a highly conserved gene ubiquitously expressed in the embryo during development ${ }^{5,6}$. It acts in many different tissues, particularly those derived from the neural crest cells (enteric nervous system and craniofacial mesoectoderm), and it is strongly expressed in the developing forebrain. It is also involved in heart septation and in the development of the midline structures (corpus callosum and genitalia), all of which imply that its alteration could lead to great phenotypic variability within this disorder?

The majority of MWS patients have de novo mutations of the $Z E B 2$ gene, with the exception of four families with recurrence ${ }^{8,9,10}$, including a pair of siblings, which suggests a germline mosaicism ${ }^{8}$. Over 170 cases $^{2}$ of $Z E B 2$ mutations have been described to date, and these mutations include whole gene deletions, small deletions/insertions, duplications, splice-site mutations, and nonsense and missense mutations.

Because mutations in ZEB2 are frequently associated with agenesis of the corpus callosum, microcephaly, epilepsy, and mental retardation, this new genetic syndrome may hold interest for pediatric neurologists. More recently, the number of patients described without HD (approximately $60 \%$ ) has been increasing, as more clinicians become aware of the traits of the facial gestalt ${ }^{2}$. Here, we have characterized seven patients with clinical and molecular diagnosis of MWS, with emphasis on their neurological aspects.

\section{METHOD}

\section{Participants}

This was a retrospective single-center study conducted in the Neurology Unit of the Instituto da Criança, Universidade de São Paulo. Patients were given a clinical diagnosis of MWS if they had the distinctive facial features associated with developmental delay or mental retardation. The medical records of each patient were reviewed, and a patient was considered to have a confirmed diagnosis of MWS if they presented with a mutation in the ZEB2 gene.

Informed consent was obtained from all participants in accordance with the Institutional Ethics Committee guidelines. Patient evaluations included a physical and neurological examination, epileptic history with seizure semiology and seizure classification according to system of the International League Against Epilepsy ${ }^{11}$, application of the Denver II scale ${ }^{12}$, brain magnetic resonance imaging (MRI) and electroencephalography (EEG) during waking and sleeping states.

\section{Mutation analysis}

ZEB2 coding exons and flanking intronic sequences were amplified using PCR from genomic DNA isolated by standard procedures and directly sequenced by the Sanger method. DNA mutation numbering was based on the ZEB2 cDNA sequence (NM 014795.3), wherein +1 corresponds to the A in the ATG translation initiation codon.

Studies of $Z E B 2$ gene deletions were conducted using two fluorescently labeled multiplex PCR reactions with two external controls, DSCR1 (chromosome 21) and F9 (chromosome X). ZEB2 molecular study was performed in the Department of molecular genetics, Hôpital Henri Mondor, Creteil, France.

\section{RESULTS}

\section{Clinical assessment}

Thirteen patients received a provisional diagnostic classification of MWS, but mutations of the ZEB2 gene were present in only seven patients ( 2 females and 5 males), ranging in age from 1 to 11 years old at diagnosis. The mean age at the last visit was 9 years and 6 months (range from 2 years and 4 months to 16 years and seven months). All patients were sporadic cases, and no consanguinity was reported.

The distinctive facial gestalt was present in all patients (Figures A and B). Birth weight and length for all of our patients were uniformly within the normal range. Postnatal growth parameters varied substantially between individuals. Height/length was noted to be at or below the $3^{\text {rd }}$ percentile in four patients. Five individuals were noted to have microcephaly, four of whom were documented to have a normal head circumference at birth. Clinical features are summarized in Table 1.

All patients had moderate to severe developmental delay and/or mental retardation. The Denver II scale ${ }^{12}$ (Table 2) was used with patients with evident and intense delay in all aspects, mainly in their fine motor, adaptive skills. Two
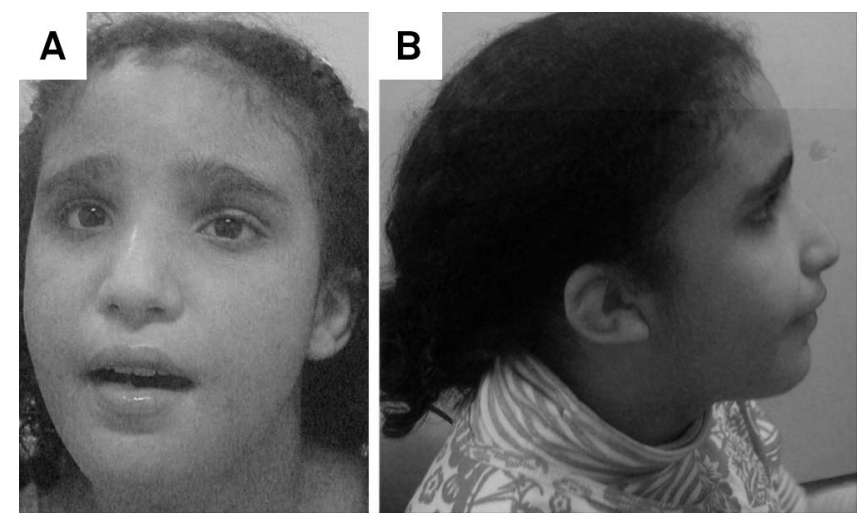

Figure. Facial appearance of patient 5, at the age of 11 years. (A) Note broad and medially flaring eyebrows, broad nasal bridge, prominent columella, and (B) low set ears, and upturned ear lobes. 


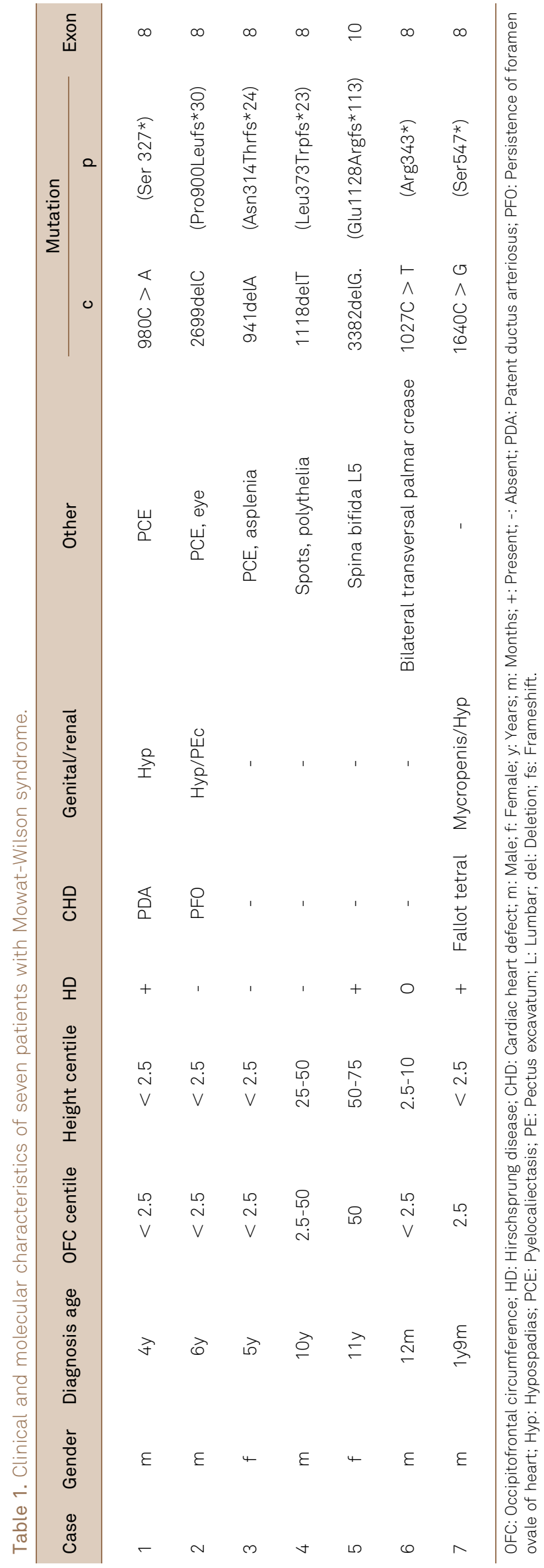

patients walked at 3 years of age, one at 5 years of age and the other at 6 years of age. Three patients were not able to walk without support. Of the ambulatory patients, all were noted to have a wide-based gait. None of the five patients older than 4 years of age was toilet trained. All individuals had impaired verbal language skills. Three patients had no spoken words. The others used limited sign language, with few words, starting between 3 and 5 years old. Receptive language was characterized as much better than expressive language in all patients. Six had significant problems with drooling. All patients were described as having a happy demeanor, three of whom also had frequent laughter.

Only patient 7 did not present with seizures; the other six individuals had focal seizures, with semiology versive in five patients and hypomotor in one patient. Secondary generalization was observed in two patients. The age of onset of seizures ranged from 8 months to 5 years (median age of 1 year and 8 months); three patients presented with seizure onset prior to 12 months of age. Three patients presented with status epilepticus (seizure time longer than 30 minutes). Seizures were more frequently observed during sleep in all patients, and two presented with seizures only during sleep. Seizures triggered by fever were observed in four patients, and in all of these patients, they represented the initial seizure. Table 3 summarizes the epileptic characteristics of the patients.

EEG was normal in two patients (including one patient who did not present with seizures and a second patient who presented with frequent seizures though the EEG was normal). All the other patients presented with abnormal EEG, including symmetric or asymmetric slowing background activity (in five patients), associated focal epileptic activity (in five patients), multifocal epileptic activity (in one), and generalized epileptic activity (in one). No specific patterns or cortical areas were observed. One patient (patient 6) presented with activation of epileptic discharges during sleep. Three patients were seizure free through therapy, two patients presented with occasional seizures despite the use of one or two drugs, and one patient presented with frequent seizures despite monotherapy. Except for the patient with no seizures, no patient was free of antiepileptic drugs.

Brain MRI was performed in all individuals. One individual had a partial agenesis of the corpus callosum with presence of the corpus callosum genu. Four individuals had complete agenesis of the corpus callosum, and MRI was normal in two patients. Subcortical gliosis of the left medial frontal gyrus was also observed in patient 1 , and in patient 6, an circumscribed oval lesion was observed, with T1 hypointensity and T2/FLAIR hyperintensity, with intense and homogeneous enhancement, and without restriction on diffusion, suggestive of astrocytoma pilocytic at the mesencephalon and left superior cerebellar peduncle. Table 4 
Table 2. Denver Developmental Screening Test II in seven patients with Mowat-Wilson disease.

\begin{tabular}{lccccccc}
\hline Case & $\mathbf{1}$ & $\mathbf{2}$ & $\mathbf{3}$ & $\mathbf{4}$ & $\mathbf{5}$ & $\mathbf{6}$ \\
\hline Age & $5 \mathrm{y} 8 \mathrm{~m}$ & $13 \mathrm{y} 1 \mathrm{~m}$ & $9 \mathrm{y} 9 \mathrm{~m}$ & $14 \mathrm{y}$ & $15 \mathrm{y} 2 \mathrm{~m}$ & $4 \mathrm{y} 11 \mathrm{~m}$ & $2 \mathrm{y} 4 \mathrm{~m}$ \\
Gross motor & 19 & 9 & 13 & 13 & 14 & 13 & 12 \\
Language & 15 & 6 & 14 & 18 & 20 & 7 & 20 \\
Fine motor/adaptive & 10 & 8 & 8 & 7 & 12 & 10 \\
Personal/social & 11 & 15 & 16 & 17 & 16 & 9 \\
\hline
\end{tabular}

Y: Year; m: Month.

Table 3. Clinical characteristics of seizures in seven patients with Mowat-Wilson disease.

\begin{tabular}{|c|c|c|c|c|c|c|c|}
\hline Case & $\begin{array}{l}\text { Age last } \\
\text { visit }\end{array}$ & Seizure type & $\begin{array}{l}\text { FTS age } \\
\text { onset }\end{array}$ & $\begin{array}{c}\text { Age onset nonfebrile } \\
\text { seizures }\end{array}$ & $\begin{array}{l}\text { Sleep } \\
\text { activation }\end{array}$ & $\begin{array}{l}\text { Antiepileptic } \\
\text { drug }\end{array}$ & $\begin{array}{c}\text { Response/status } \\
\text { epilepticus }\end{array}$ \\
\hline 1 & $5 y 8 m$ & focal & $1 \mathrm{y} 5 \mathrm{~m}$ & $4 y$ & + & OXC & $3 /-$ \\
\hline 2 & $13 y 1 \mathrm{~m}$ & focal & - & $5 y$ & + & PB & $1 /+$ \\
\hline 3 & $12 \mathrm{y} 10 \mathrm{~m}$ & focal & $8 m$ & $2 y$ & ++ & CBZ & $2 /+$ \\
\hline 4 & $14 y 7 m$ & $\begin{array}{l}\text { focal/secondary } \\
\text { generalization }\end{array}$ & $10 m$ & $2 y 11 m$ & ++ & VPA/CLB & $1 /+$ \\
\hline 5 & $16 y 7 m$ & focal & - & $9 m$ & + & VPA & $1 /-$ \\
\hline 6 & $7 y 6 m$ & $\begin{array}{l}\text { focal/secondary } \\
\text { generalization }\end{array}$ & $1 \mathrm{y} 2 \mathrm{~m}$ & $2 y 4 m$ & + & CBZ/NZP & $2 /-$ \\
\hline 7 & $3 y 2 m$ & - & - & - & - & - & - \\
\hline
\end{tabular}

FTS: Fever-triggered seizure; y: Year; m: Month; OXC: Oxcarbazepine; VPA: Valproic acid; CBZ: Carbamazepine; CLB: Clobazam; NZP: Nitrazepam; -: Negative; +: Positive; ++: Exclusive; 3: Frequent seizures; 2: > 50\% reduction; 1: Seizure free.

summarizes the electrographic and neuroimaging characteristics of the patients.

\section{Mutation analysis}

A ZEB2 mutation was identified in seven of the twelve studied patients. Patients 1 and 2 had ZEB2 mutations that have been previously reported by Dastot-Le Moal et al. ${ }^{13}$. Nonsense mutations were observed in three patients, and frameshift mutations were observed in four. Table 1 shows the clinical and molecular characteristics of the seven patients.

\section{DISCUSSION}

The exact incidence and natural history of MWS are still unknown, but based on the number of patients identified in a short period of time, MWS appears to be more unrecognized than uncommon. The prevalence of males with MWS was initially described in the literature (male/female ratio from 2:1 to $3: 1)^{14}$, and we found a 5:2 ratio. However, the latest reports have found an overall male/female ratio near 1:19,15. All cases reported to date are from different ethnic backgrounds.

Although there is no consensus, Adam et al. ${ }^{15}$ propose some criteria for the diagnosis of MWS, including the presence of developmental delay or mental retardation and prominent nasal tip with low-hanging columella, at least one other distinctive facial feature and at least one of the following: HD, seizures, agenesis or hypoplasia of the corpus callosum. Our case series fulfill these criteria. According to Zweier et al. $2005^{9}$, only patients with a characteristic facial phenotype harbored a molecular lesion, emphasizing the specificity of the facial gestalt as a predictor of the ZEB2 gene defect. The changing phenotype with age tends to

Table 4. Electroencephalographic, and neuroimaging characteristics of seven patients with Mowat-Wilson disease.

\begin{tabular}{lcccc}
\hline Case & Initial EEG & Evolution EEG & MRI \\
\hline 1 & Normal & Normal & CCA, L medial frontal \\
subcortical gyrus gliosis \\
CCA
\end{tabular}

EEG: Electroencephalography; MRI: Magnetic resonance image; CCA: Corpus callosum agenesis; L: Left; R: Right; BA: Background activity; C: Central; P: Parietal; F: Frontal; ShW: Sharp wave; SIW: Slow wave. 
make the diagnosis easier to recognize, although some distinctive features, as the uplifted ear lobules, are present even in infancy. During early childhood, however, the typical sparse medially flared eyebrows tend to become less obvious, while later on, the prognathism with a "chisel-shaped" chin and the overhanging nasal tip with a low-hanging columella contribute to a rather distinctive facial phenotype. Growth parameters are usually normal at birth, but the majority developed both postnatal microcephaly, and short stature (five in seven patients). Notably, several children were within the normal range for occipitofrontal circunference (OFC) and height.

Of the seven patients described here, all have moderate to severe psychomotor delay. Achievement of motor milestones in individuals with MWS is delayed, with a median age of walking of 4 years in our study. Others studies reported an average age of walking between 3 and 4 years old $^{14,15}$. However, it should be noted that not everyone with this condition will achieve ambulation ${ }^{14}$. Patients have often been described as having a wide-based or ataxic-like gait, which may not improve with time. This gait, combined with their happy demeanor, frequent laughter, and arm positioning has led some individuals to be given a presumptive diagnosis of Angelman syndrome. However, the facial features and the absence of malformations or HD should distinguish Angelman syndrome from MWS patients. Delayed ambulation may be exacerbated by the findings of pes planus with calcaneovalgus positioning. A referral to orthopedics, physical therapy and occupational therapy should be instituted early in this condition. Language skills were also impaired. Only three patients could speak isolated words, starting at a median age of 6 years in our study.

Seizure disorder is a very common manifestation found in approximately $70 \%-75 \%^{9,16,17,18}$ of patients; in the present study, epilepsy was present in all but one patient. The patient who did not develop seizures was the youngest of the group, and we need to maintain follow up in order to watch for the potential future development of seizures. Therefore, individuals with MWS should be considered to be at high risk for developing seizures during childhood, and their parents and healthcare providers should be properly counseled.

Seizure onset varies considerably from the neonatal period to 9 years old, most commonly presenting within the second year of $\mathrm{life}^{14}$. In our group, similarly to the literature, the first seizure occurred at a mean age of 1 year and 8 months, and in three patients, it occurred within the first year of life, in contrast with the observations of Cordelli et al., who rarely observed the start of epilepsy in the first year of life $\mathrm{e}^{19}$.

A fever-triggered seizure, in most cases, is the first seizure and is frequent ${ }^{19}$; fever-triggered seizure was observed in four patients of our patients, at a median age of 1 year and 2 months. Nonfebrile seizures typically started usually afterwards, with a mean age of onset of 2 years and 10 months (varying from 9 months to 5 years). Another seizure characteristic was apparent activation during sleep, also observed in a previous study ${ }^{19}$. All of our patients presented frequent seizures during sleep, and two of them presented with exclusively sleep seizures. In our group, all patients presented with focal seizures, and, unlike Cordelli et al. ${ }^{19}$, atypical absence seizures were not observed. No specific EEG pattern or cortical area was observed in our patients, but in one patient in this series, activation of EEG abnormalities during sleep was observed, as described previously ${ }^{19}$.

Seizures tend to become easier to manage with age ${ }^{17}$. Severe seizures, however, were observed in three patients, with presence of status epilepticus, and all of our patients required follow up with the use of antiepileptic medications.

A distinct electroclinical phenotype was suggested by Cordelli et al. ${ }^{19}$, characterized by focal and atypical absence seizures, often preceded by fever-triggered seizures, and agedependent EEG changes. We could also suggest including the presence of sleep-related seizures in this phenotype, and more EEG studies during sleep will be necessary to delineate the disease.

In many cases, the cause of seizures cannot be attributed to gross structural brain abnormalities. Zweier et al. ${ }^{9}$ suggested that a gene responsible for early seizures with a lethal course might be located between BAC RP11-207014 at $145.3 \mathrm{Mb}$ and marker D2S2299 at $152.2 \mathrm{Mb}$, where at least one gene related to epilepsy, CACNB4, is known to be located, but further analysis in more patients is required to confirm this association.

The most consistent finding from brain MRI, both in the literature and in our series, is hypoplasia or agenesis of the corpus callosum (agenesis in four patients and partial agenesis in one patient). While significant brain malformations or neuronal migration defects are not typically seen in MWS patients, several individuals have been reported with cerebral atrophy, poor hippocampal formation, or frontotemporal hypoplasia with or without temporal dysplasia ${ }^{14}$. The utility of performing brain MRI in a patient with suspected MWS is primarily to aid in diagnosis, as the finding of agenesis of the corpus callosum is a significant positive predictor of MWS'. We found three patients without agenesis of the corpus callosum, but without an apparent difference in motor or cognitive achievement from the others.

As in patient 6 in our casuistic, Valera et al. described the association of MWS with two different brain tumors (medulloblastoma and glioblastoma) in the same child and speculated that the ZEB2 mutation could predispose to brain cancer in those patients ${ }^{20}$.

The seven cases of MWS here reported increase the number of patients with ZEB2 mutations. As in the literature, the 
majority of mutations in our series were localized in exon 8 (6/7 cases), which contains $60 \%$ of the coding sequence ${ }^{2}$. No genotype-phenotype correlation could be observed.

It seems likely that more patients will be described with MWS with careful and detailed observations of the clinical features by clinical geneticists, pediatricians, and neurologists. Thus, it will be possible to elucidate the true clinical spectrum and the natural history of this syndrome. With this series, we wish to contribute to a further delineation of this peculiar entity.

\section{References}

1. Mowat DR, Croaker GD, Cass DT, et al. Hirschsprung disease, microcephaly, mental retardation, and characteristic facial features: delineation of a new syndrome and identification of a locus at chromosome 2q22-q23. J Med Genet. 1998;35:617-23.

2. Mowat D, Wilson M. Mowat-Wilson syndrome. In: Cassidy SB, Allanson JE, editors. Management of genetic syndromes. 3rd ed. New Jersey: John Wiley and Sons; 2010.

3. Cacheux V, Dastot-Le Moal $F$, Kääriäinen $H$, et al. Loss of function mutations in SIP1 Smad interacting protein 1 result in a syndromic Hirschsprung disease. Hum Mol Genet. 2001;10:1503-10.

4. Wakamatsu N, Yamada Y, Yamada K, et al. Mutations in SIP1, encoding Smad interacting protein-1, cause a form of Hirschsprung disease. Nat Genet. 2001;27:369-370.

5. Watanabe M, Whitman M. FAST-1 is a key maternal effector of mesoderm inducers in the early Xenopus embryo. Development. 1999;126:5621-5634.

6. Shi Y. Structural insights on Smad function in TGFbeta signaling. Bioessays. 2000;23:223-232.

7. Espinosa-Parrilla $Y$, Amiel J, Augé J, et al. Expression of the SMADIP1 gene during early human development. Mech Dev. 2002;114:187-191.

8. McGaughran J, Sinnott S, Dastot-Le Moal F, et al. Recurrence of Mowat-Wilson syndrome in siblings with the same proven mutation. Am J Med Genet. 2005;137:302-304.

9. Zweier C, Thiel CT, Dufke A, et al. Clinical and mutational spectrum of Mowat-Wilson syndrome. Eur J Med Genet. 2005;48:97-111.

10. Ohtsuka M, Oguni $\mathrm{H}$, Ito $\mathrm{Y}$, et al. Mowat-Wilson syndrome affecting 3 siblings. J Child Neurol. 2008;23:274-278.
11. Berg AT, Berkovic SF, Brodie MJ, et al. Revised terminology and concepts for organization of seizures and epilepsies: report of the ILAE Commission on Classification and Terminology, 2005-2009. Epilepsia. 2010;5:676-685.

12. Frankenburg WK, Dodds JB, Archer P, et al. The Denver II: a major revision and restandardization of Denver Developmental Screening Test. Pediatrics. 1992;89:91-97.

13. Dastot-Le Moal F, Wilson M, Mowat D, et al. ZFHX1B mutations in patients with Mowat-Wilson Syndrome. Hum Mutat. 2007;28:313-321.

14. Mowat DR, Wilson MJ, Goossens M. Mowat-Wilson syndrome. J Med Genet. 2003;40:305-310

15. Adam MP, Schelley S, Gallagher R, et al. Clinical features and management issues in Mowat-Wilson syndrome. Am J Med Genet. 2006;140:2730-2741.

16. Ishihara N, Yamada K, Yamada Y, et al. Clinical and molecular analysis of Mowat-Wilson syndrome associated with ZFHX1B mutations and deletions at 2q22-q24.1. J Med Genet. 2004;4:387-393.

17. Wilson M, Mowat D, Dastot-Le Moal F, et al. Further delineation of the phenotype associated with heterozygous mutations in ZFHX1B. Am J Med Genet. 2003;119:257-265.

18. Garavelli L, Zollino M, Mainardi PC, et al. Mowat-Wilson syndrome: facial phenotype changing with age, study of 19 Italian patients and review of the literature. Am J Med Genet 2009;149:417-426.

19. Cordelli DM, Garavelli L, Savasta S, et al. Epilepsy in Mowat-Wilson syndrome: delineation of the electroclinical phenotype. Am J Med Gene. 2013;161:273-284.

20. Valera ET, Ferraz ST, Brassesco MS, et al. Mowat-Wilson syndrome: the first report of an association with central nervous system tumors Childs Nerv Syst. 2013;29:2151-2155. 